\title{
Factors Affecting Students' Intention to Use Massive Open Online Courses
}

\author{
An Minh Ngoc Pham ${ }^{+}$, \\ Thao Lai Phuong Pham, \\ Gam Hong Huynh, \\ Thu Hoang Minh Vo, \\ Anh Ngoc Kim Nguyen, \\ Tri Minh Tran
}

\section{Article history}

Received: 03 September 2021 Accepted: 18 December 2021 Published: 30 December 2021

\section{Keywords}

MOOCs, Technology

Acceptance Model, learning strategies, EFL students

\author{
Can Tho FPT University, Vietnam \\ +Corresponding author • Email: anpmn@fpt.edu.vn
}

\begin{abstract}
Massive Open Online Courses (MOOCs) attract many researchers because of their massiveness, openness, machine and peer assessment, yet there are still many questions to be answered. This study was conducted at FPT University in Can Tho during the 2020-2021 academic year using the quantitative approach. A purposeful sampling technique was used to select 226 participants who partook at least one MOOC on the Coursera platform. The questionnaire consists of 18 items adapted from Technology Acceptance Model (TAM) developed by Davis (1989), and Learning Strategies, by Marton and Säljö (1976). The findings showed that perceived ease of use (PEOU), and perceived usefulness (PU) have a great impact on students' intention to use MOOCs in the future, PU, however, has a stronger and more direct correlation to the acceptability of MOOCs. Furthermore, surface learning strategy has a negative effect on the intention to enroll in MOOCs while deep learning strategy was not significantly correlated with intended future use of MOOCs. More importantly, a valuable finding was that surface learning strategy was in inverse proportion to courses variable and it can be lessened. Our findings are expected to offer a multi-dimensional view for students, especially those in the current context as well as MOOCs developers in order to design curricula.
\end{abstract}

\section{INTRODUCTION}

The development of the education and training systems with the application of information technology has been widely welcomed by universities and countries around the world, meeting the increasingly diverse and plentiful learning needs. This refers to the method of learning with MOOCs (Massive Open Online Courses), which are online courses for those who are motivated to study anytime, anywhere in the world through a smart device with Internet connection (Jordan, 2014). It is an highly accessible learning environment with breakthrough innovations and greater convenience than the traditional classroom (Dyer, 2014). Currently, MOOCs have gained significant coverage in the higher education system (eg, Bates, 2014; Pence, 2012). The main features of MOOCs are a large number of students, online and open lectures provided in video format (8-12 minutes) followed by structured quizzes, and self-controlled learning pace, as the key characteristics, as well as online forums, peer support requests, discussions, peer-reviewed and/or self-assessment projects (Glance et al., 2012). However, because it is impossible for a human instructor to examine and score all assignments, they are typically either machine graded or evaluated by classmates in the class. According to data from the University of Pennsylvania Graduate School of Education (2013), MOOCs have small 
engagement rates, students' "engagement" decreases significantly after the first two weeks of the course, and just few students complete the course. Moreover, MOOCs have been considered a component of the curriculum in many schools.

According to Markoff (2013), while thousands of people sign up for MOOCs, only a tiny percentage ultimately complete them. For instance, the poor completion rates of MOOCs have been criticized for often being below $10 \%$ (Jordan, 2013). Bioelectricity at Duke University (Belanger \& Thornton, 2013) enrolled 12,175 students in the Fall 2012 semester. However, only 7,761 students viewed a video; 3,658 students completed a minimum of one quiz; 345 students tried the final test, and only 313 students received a certificate. The typical dropout rate is believed to be between $91 \%$ and $93 \%$. Likewise, Meyer (2012) claimed that, the dropout rates of Stanford, MIT, and UC Berkley MOOCs were $80 \%$ to $90 \%$ and just $7 \%$ of the 50,000 students that took the Coursera-UC-Berkeley Software Engineering course completed it.

In Vietnam, GiapSchool was the first firm to open a MOOC's portal that contains plenty of courses with multiple disciplines in 2013. In 2015, FPT joined the race through another start-up project named FUNiX. Hien Nguyen, an online education research specialist, in a statement in 2016 stated that Vietnam had about 150 MOOCs start-ups in higher education (Sang \& Tai, 2017). To date, the five leading market players in Vietnam are Topica, FUNiX, Kyna, Tienganh123, and eGroup. More importantly, in the current context, FPT University in Can Tho, is credited as one of the first institutions to use this training method, yet the dropout rates are rather high (but notably better than those of Stanford and Berkeley), at approximately 30\%. The question raised is what can stimulate students to continue to attend (or complete) MOOCs?

From the above-discussion, it can be seen that MOOCs are an educational innovation and are widely accepted by many institutions, especially in the outbreak of the Covid-19 pandemic recently. The TAM model explores the cognitive elements that influence technology acceptance, and the model implies that the new technology's perceived usefulness and perceived ease of use are both important. It also identifies the elements that influence students' intentions to use MOOCs as an online educational tool to promote learning activities. However, there is little research on students' attitudes toward MOOCs learning. Plus, there would be a huge shortcoming if students' perceptions when approaching MOOCs is ignored. Therefore, this paper aims to contribute to the novel education- MOOCs. Specifically, it is supposed to examine students' experiences in MOOCs to determine which variables are most predictive for MOOCs' future use. This finding would makes a significant contribution at FPT university which uses MOOCS as a compulsory part of the curriculum. Moreover, the results of the current study are likely to provide MOOCS' creators with an insightful look when designing curricula and students, particularly those in the current setting, with a clearer perspective when joining MOOCs. To fulfill the research objectives, the two research questions were raised as follows: (1) What are students' attitudes towards future use of MOOCs through the TAM?; (2) How do learning strategies influence students' attitudes towards future use of MOOCs?

\section{LITERATURE REVIEW}

\subsection{MOOCs}

Massive Open Online Courses (MOOCs) get their name from the word "massive", which denotes that this type of education appeals to a large number of individuals. The system is designed to accommodate a high number of students. The term "open" alludes to the fact that these courses are available to anybody who is willing to join and they are free. The term "online" denotes that these classes are delivered through the Internet using interactive resources such as videos, presentations, and audio (Kesim \& Altınpulluk, 2015). In addition, MOOCs have garnered worldwide attention as a new option for learning over the past several years as large-scale open online courses with publicly shared curriculum. Moreover, they are considered a means of forcing a new outlook on digital teaching and learning practices (Chen, 2014). MOOCs are a combination of innovations and the use of technology that provide learning opportunities for a vast number of individuals (Siemens, 2013). Taking into account the above definitions, current research, and online platforms presented throughout this paper, we propose a working definition of a MOOC as follow: A MOOC is an Internet-based course designed to create an educational environment via online resources (e.g., videos, assignments, and exams), employing distance education pedagogies (networked learning methods, connectivist approaches), and delivering assigned instruction through accessible web-based software on a global scale to plenty of learners that access voluntarily for either personal or professional development interests.

MOOCs are currently being applied to online and offline classes (online via courses on COURSERA platform and offline in blended learning courses), and are used by educational institutions worldwide. Students who have 
access to MOOCs would have high level of proficiency in English as well as communication. MOOCs are classified into three main types: xMOOCs, cMOOCs and quasi-MOOCs (Siemens, 2013).

\section{- cMOOCs}

The $\mathrm{c}$ stands for connectivist. cMOOCs are a loosely structured online group of learners with a similar objective in a subject field who use social networking sites and informal contact to learn from each other and express their mutual understanding of the course content. Participants in a cMOOC serve as both professors and students in the course, sharing thoughts and participating in a collaborative teaching and learning process by intensive interaction and advancement of technology. Teachers are extremely visible in extended online courses; the teaching function can be accomplished in a variety of methods, such as through content delivery in a recorded lecture, written textbook, facilitation of a synchronous video conference, co-participation in online discussions, or even through an automated mailing list in MOOCs (Ross et al., 2014). In online courses, learners can access different reference materials as they can receive information directly from the teacher and process it the way they want. They can consult and seek guidance from an advisor through mandatory access methods. Connectivist MOOCs do not have a centralized platform and encourage participants to meet and self-organize in other locations.

\section{- $x M O O C s$}

The $\mathrm{x}$ stands for extended course, which refers to a classroom that has been extended online. The concept is also used to describe the first open courses. They meet as a large number of people by presenting course material online. xMOOCs are a form of online comment course that uses more traditional higher education training techniques including pre-recorded lectures, texts, and quizzes. The pedagogical model that underpins these courses is one of "teacher as expert" and "learner as knowledge consumer." They are often offered by colleges or private institutions and can award certificates and/or course grades. xMOOCs, which are based on traditional university classes, are designed to give more students access to higher education. Major xMOOC providers are Coursera, Udacity and Udemy (Chen, 2014).

\section{- Quasi-MOOCs}

Quasi-MOOCs are web-based, either make use of online training, or have online classes, or represent an online resource, such as Khan Academy or MIT OpenCourseWare. Quasi-MOOCs are created online by teachers who may or may not be accredited. The aim of the quasi-MOOC is to give students access to a series of free mini-lectures in a variety of disciplines and for students of various ages. This type of MOOC is completely different from a cMOOC, in aspect of the social interaction, and $\mathrm{xMOOC}$ in the realm of the automated-grading and tutorial-driven format.

\subsection{Theoretical Framework}

\section{- Technology Acceptance Model}

Information technology acceptance has received significant attention in the last decade in the field of language education. The Technology Acceptance Model (TAM) is one of the most commonly used models to explain an individual's acceptance of information technology systems and its effect on individuals' continued intention to use MOOCs. TAM was adapted from the Theory of Reasoned Action (TRA), simplified from TRA, and proposes two additional constructs of perceived usefulness (PU) and ease of use (PEOU). The Theory of Reasoned Action (TRA) explains the relationship between people's attitudes and subjective norms to predict how individuals will behave based on their pre-existing attitudes and behavioural intentions. This study used the "technology acceptance modelTAM" (Davis, 1989) because of various reasons including: TAM was created to anticipate and explain users' adoption and usage of information technology. TAM has been employed in a variety of technology-related fields and circumstances, and it is also acknowledged as an important model appropriate for investigating the adoption of various online learning technologies. According to Davis (1989), Perceived ease of use (PEOU) refers to an individual's ease of using technology. Perceived usefulness (PU) refers to improving work performance or academic achievement thanks to the technology. The previous study in Education and Information Technologies has experimentally proven that PU and PEOU are the main determinants of e-learning adoption (Al-Gahtani, 2016; Vululleh, 2018). Both PU and PEOU, in particular, are significant factors affecting learners' intention to use (IU) and to adopt e-learning. The more simple to use MOOCs are judged, the more learners will see MOOCs as a helpful tool for achieving their learning objectives. In light of the above, the first two research hypotheses will be:

H1: PU has a positive effect on students' continued intention to use MOOCs.

$\mathrm{H} 2$ : PEOU has a positive effect on students' continued intention to use MOOCs. 


\section{- Learning strategies}

Students' learning strategies are one aspect that influences their attitudes towards MOOCs. According to the research by Marton and Säljö in 1976, learning strategies include two main types: deep learning strategy and surface learning strategy. Students who know how to choose the best learning method for themselves will grasp the goal more easily and quickly. Besides, it will exert positive impact on their learning quality. For MOOCs, when deep learning and surface learning strategies are well applied in learning, learners will be more active in selecting and absorbing knowledge. Therefore, using learning strategies will help learners have a better view of MOOCs and intend to use them in the future.

Deep learning is a technique of collecting insights and significance from course content and perspectives (Warburton, 2003). Furthermore, deep learning is key in the development of teaching and learning for long-term sustainable practices. Deep learners can discover more topics in a lesson, which can help them expand their knowledge and construct lessons in the most effective way. Deep learners were able to increase their performance in a multi-stage online peer evaluation exercise more than their surface counterparts (Yang \& Tsai, 2010).

Surface learning is a kind of adopting actual information and thoughts without questioning; and seeking to categorize them as separate, unrelated objects. It's a shallow method of learning that entails skimming the surface of the topic being studied and focusing solely on the evaluation criteria, rather than delving deeper. Surface learners prefer to work alone and consider learning as a means of completing tasks, as opposed to deep learners who strive to comprehend the meaning. Students who have this learning strategy just strive to complete their learning tasks as quickly as possible without asking any more questions or completely comprehending the content of the material.

According to a prior study focusing on library and information science (LIS) students (Aharony, 2009) students who adopt deep learning strategies are more motivated to learn about Web 2.0 applications and environments, since they use them more than surface learners. The adoption of MOOCs by students in the future might be predicted based on deep and surface learning techniques. Assuming that deep and surface learning strategies might speculate students' MOOCs future use, two additional hypotheses of this study are:

H3: Deep learning strategy has a positive effect on students' continued intention to use MOOCs.

H4: Surface learning strategy has a negative effect on students' continued intention to use MOOCs.

\subsection{Previous Studies}

The development of technology has been altering training models and influencing the strategies of educational institutions, particularly in the adaptation of the MOOCs model. There is no doubt that MOOCs have brought about a variety of benefits for a broad range of learners. Compared to traditional online courses, MOOCs are larger in scale and have a worldwide distribution. Therefore, there has been plenty of research undertaken with the aim of investigating every aspect of MOOCs.

Recently, Abir Jaafar Husain et al. (2018) with the study "Analyzing Learners Behavior in MOOCs: An Examination of Performance and Motivation Using a Data-Driven Approach", found that the interaction of learners is also one of the reasons why we care about students' learning outcomes. His research concludes that there are still cases where students tend to drop out due to reasons such as lack of motivation, fatigue and boredom. Two studies by Wanli Xing \& Dongping Du (2018) and Aldowah, H. et al (2019), also investigated the dropout rate in MOOCs, then showed that MOOCs are often enormous in size with theoretically unlimited enrollment and allow anyone to participate, resulting in a high dropout rate. Moreover, examinations are possibly the most challenging thing to perform online, and the structure of an online exam differs significantly from a traditional exam in which the proctor interacts directly with students. Several research papers on the effectiveness of using MOOCs also detailed how the online tests are administered. For instance, Tuan Nguyen (2015) and Khawater (2021) showed that the way to assess learning outcomes in online classes is more effective and convenient than in traditional classes.

So far only a few studies have addressed students' attitudes towards MOOCs. Taylor \& Todd (1995) and Sattari et al. (2017) suggested that social influence has direct effects on attitude. This means that the attitude of students towards the use of MOOCs depends significantly on the attitudes of their friends, lecturers, and schools towards MOOCs. The largest-scale study followed a MOOC run on Coursera on bioelectricity by Roger Barr from Duke University (Belanger \& Thornton, 2013). The participants in this course answered both pre-and post-course survey questions. Whereas the total number of students in the pre-course survey was not mentioned, the post-course survey was completed by 105 students. The objective of the surveys was to grasp motivations for enrolling; to learn about 
students' activities during the course; their attitude towards it; and factors promoting and difficulties to course completion. More recently, the studies by Wu and Chen (2017) and Hoi (2020) showed that performance expectancy directly affects MOOC attitude and indirectly affects MOOC use. This explains that if students believe MOOCs help them improve their academic performance, they will develop a positive attitude toward them and use them.

Because of the proliferation of MOOCs, it is vital to understand whether or not students are willing to accept this novel learning approach given that courses are massive and students' evaluations are quite dissimilar. Furthermore, instructors, mentors, tertiary education governors, and even course designers should be conscious of obstacles students encounter and how to support them. In the current research, we will focus on students' learning strategies and attitudes to understand what influences positively on students' attitudes towards learning in MOOCs. We do believe that the research outcomes may make a contribution to the knowledge of variables that impact students' attitudes towards MOOCs.

\section{MATERIALS AND METHODS}

\subsection{Sample}

According to Mueller (1997), the ratio of the samples size to the number of observed variables should be between 10:1 and 15:1 (Mueller, 1997; Thompson, 2000). In our study, there are 18 variables, so the sample size should be in the range from 180 to 270 . The 226 participants who experienced at least one MOOC were selected from all majors at FPT University in Can Tho including students majoring in Business Administration, Information Technology, and Linguistics which account for 36,3\%,36,7\%, and $27 \%$ of enrolled students respectively. Among all the respondents, males accounted for $51,3 \%$ and females $48,7 \%$.

\subsection{Research Instruments}

In order to understand the perceptions of FPT University students about their experiences in MOOC courses. A questionnaire was devised with two sections.

The first part concerns general information about the participants including gender, current year of study, major, courses the subjects participated in via Coursera platform, and whether or not students intend to use MOOCs in the future with two compulsory options (yes or no).

The second part consists of items concerning the basic constructs of the research model. They are arranged to examine Perceived Usefulness (three items); Perceived Ease of Use (three items) based on Liu, Li, and Carlsson (2010), and Learning Strategies (twelve items) which are validated by Aharony (2009, 2014b). Learning Strategies include two factors: deep learning strategies (five items) and surface learning strategies (seven items). This part adopts the 5-point Likert-type scale with $1=$ strongly disagree and $5=$ strongly agree.

To test the reliability of the survey used, from Jun 14th to Jun 29th, the questionnaire was distributed randomly to forty students at FPT University in Can Tho who experienced at least one MOOC as a requirement in an offline course. According to Pallant (2007), the acceptable level for alpha value is above 0.7. Cronbach's Alpha for perceived usefulness (PU) factor was 0.878, perceived ease of use (PEOU) 0.903, surface learning strategy and deep learning strategy 0.839 and 0.861 respectively. Therefore, the Cronbach's Alpha values of questionnaire items were high.

Table 1. The reliability of the questionnaire

\begin{tabular}{cccc}
\hline \multirow{2}{*}{$\begin{array}{c}\text { Number of } \\
\text { participants }\end{array}$} & Name of variables & Number of items & Reliability (a) \\
\hline \multirow{3}{*}{40} & PU (perceived usefulness) & 3 & 0.878 \\
\cline { 2 - 4 } & PEOU (perceived ease to use) & 3 & 0.903 \\
\cline { 2 - 4 } & SLS (Surface Learning Strategy) & 7 & 0.839 \\
\cline { 2 - 4 } & DLS (Deep learning Strategy) & 5 & 0.861 \\
\hline
\end{tabular}

\section{RESULTS AND DISCUSSION}

\subsection{Results}

In order to examine the relationship between a demographic variable, PU, PEOU, learning strategies, and MOOC future use (O4), the number of courses the participants experienced (CR), Pearson correlations were computed, which are shown in Table 2. 
Table 2. Pearson correlation between a demographic variable, PU, PEOU, learning strategies and MOOC future use $(N=226)$

\begin{tabular}{|c|c|c|c|c|c|c|c|}
\hline \multicolumn{8}{|c|}{ Correlations } \\
\hline & & $\mathrm{CR}$ & $\begin{array}{l}\text { SURFACE } \\
\text { LEARNING }\end{array}$ & $\begin{array}{c}\text { DEEP } \\
\text { LEARNING }\end{array}$ & $\begin{array}{l}\text { PERCEIVED } \\
\text { USEFULLNES } \\
\mathrm{S}\end{array}$ & $\begin{array}{l}\text { PERCEIVED } \\
\text { EASE OF } \\
\text { USE }\end{array}$ & 04 \\
\hline \multirow[t]{3}{*}{$C R$} & Pearson Correlation & 1 &,$- 194^{* \prime}$ &,- 086 & -.045 &.,- 113 & -.110 \\
\hline & Sig. (2-tailed) & & .003 & .200 & .502 & .090 & .100 \\
\hline & N & 226 & 226 & 226 & 226 & 226 & 226 \\
\hline \multirow[t]{3}{*}{ SURFACE LEARNING } & Pearson Correlation &,$- 194^{*}$ & 1 & $.458^{* \prime}$ & $301^{*}$ & $.426^{* \prime}$ & .033 \\
\hline & Sig. (2-tailed) & .003 & & .000 & .000 & .000 & .621 \\
\hline & $\mathrm{N}$ & 226 & 226 & 226 & 226 & 226 & 226 \\
\hline \multirow[t]{3}{*}{ DEEP LEARNINO } & Pearson Correlation & -.086 & $.458^{\prime \prime}$ & 1 & $.496^{*}$ & $.500^{*}$ & $.258^{\circ}$ \\
\hline & Sig. (2-tailed) & .200 & .000 & & .000 & .000 & .000 \\
\hline & $\mathrm{N}$ & 226 & 226 & 226 & 226 & 226 & 226 \\
\hline \multirow{3}{*}{$\begin{array}{l}\text { PERCEIVED } \\
\text { USEFULNESS }\end{array}$} & Pearson Correlation &,- 045 & $.301^{\prime \prime}$ & $.496 "$ & 1 & $.486 "$ & $.340^{\circ}$ \\
\hline & Sig. (2-tailed) & .502 & .000 & .000 & & .000 & .000 \\
\hline & $\mathrm{N}$ & 226 & 226 & 226 & 226 & 226 & 226 \\
\hline \multirow{3}{*}{$\begin{array}{l}\text { PERCEIVED EASE OF } \\
\text { USE }\end{array}$} & Pearson Correlation & -.113 & $.426^{\prime \prime}$ & $.500 *$ & $.486^{*}$ & 1 & $.207^{\circ}$ \\
\hline & Sig. (2-tailed) & .090 & .000 & .000 & .000 & & .002 \\
\hline & N & 226 & 226 & 226 & 226 & 226 & 226 \\
\hline \multirow[t]{3}{*}{04} & Pearson Correlation & -.110 & .033 & $.258^{*}$ & $.340^{*}$ & $207^{*}$ & 1 \\
\hline & Sig. (2-tailed) & .100 & .621 & .000 & .000 & .002 & \\
\hline & $N$ & 226 & 226 & 226 & 226 & 226 & 226 \\
\hline
\end{tabular}

There is a strong correlation between perceived ease of use, perceived usefulness, deep learning strategies, and students' intention to continue MOOC use. The result indicates that the higher level of PU and PEOU, and the deeper learners they are, the more likely MOOCs' future use will be. Furthermore, regarding the correlations between the research variables themselves, significant positive correlations were found between surface learning strategies, PU, PEOU, and deep learning strategies; Therefore, the higher level of PU and PEOU, and the more surface learning the students have, the deeper learner they are. Addressing the course variable, significant negative correlations were found between courses and surface learning strategy. In other words, the more courses students experience, the less surface learning strategy they get in MOOC.

In addition, we also carried out binary regression using MOOC future use as a dependent variable. The predictors were entered in four steps: surface learning, deep learning, PU, and PEOU.

\section{Table 3. Omnibus Tests of Model Coefficients}

\begin{tabular}{ccc|c|c} 
& & Chi-square & df & Sig. \\
\hline \multirow{3}{*}{ Step 1 } & Step & 37.545 & 4 & 0.000 \\
\cline { 2 - 5 } & Block & 37.545 & 4 & 0.000 \\
\cline { 2 - 5 } & Model & 37.545 & 4 & 0.000 \\
\hline
\end{tabular}

The Omnibus tests of model coefficients are given in Table 4. Chi-square test showed sig. $=0.000$ and $<0.05$, which means the regression model was appropriate and statistically significant.

\section{Table 4. Result of the predicted model}

\section{Classification Table ${ }^{\mathrm{a}}$}

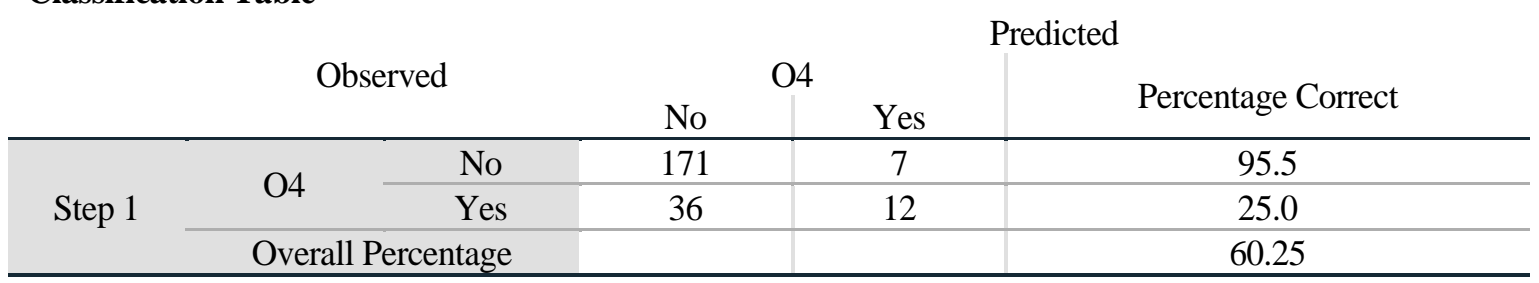

(a. The cut value is 0.500)

Table 4 showed the classification of subjects who did not intend to learn using MOOCs in the future and intended to continue learning MOOCs in the future based on two criteria: actual observation and prediction.

From Table 4 we can conclude that:

- In 178 cases of observation subjects who did not intend to learn MOOCs anymore, it was predicted that there were 171 cases that did not intend to learn, the correct prediction rate was $171 / 178=95.5 \%$.

- In 48 observed cases who continue to learn MOOCs, it is predicted that 12 cases will maintain their desire to learn MOOCs in the future, the correct prediction rate is $12 / 48=25 \%$.

- Thus, the average probability of correct prediction was $(95.5+25) / 2=60.25 \%$. 
Table 5. Binary regression coefficients of students' MOOC future use $(N=226)$

\begin{tabular}{|cc|c|c|c|c|c|} 
& & B & S.E. & Wald & df & Sig. \\
\hline \multirow{3}{*}{ Step $1^{\text {a }}$} & Surface Learning & -0.595 & 0.260 & 5.215 & 1 & 0.022 \\
\hline & $\begin{array}{c}\text { Deep Learning } \\
\text { Perceived Usefulness }\end{array}$ & 0.487 & 0.293 & 2.758 & 1 & 0.097 \\
\cline { 2 - 7 } & $\begin{array}{c}\text { Perceived Ease of Use } \\
\text { Constant }\end{array}$ & 0.228 & 0.245 & 0.864 & 1 & 0.000 \\
\hline & -6.102 & 1.177 & 26.866 & 1 & 0.353 \\
\hline
\end{tabular}

Table 5 presents the coefficient of binary regression of respondents' MOOC future use. As we can see from the table, surface learning and perceived usefulness affect the variance of MOOC future use ( $\mathrm{Sig}=0,022$ and $\mathrm{Sig}=0,000$ respectively, and $<0,05$ ) while the others with Wald test $\mathrm{Sig}>0,05$, proving that they do not impact the ability to continue learning MOOCs. In respect to surface learning, its beta coefficient is negative. In other words, the less surface learning students have, the more likely their MOOC future use will be. In terms of perceived usefulness, the beta coefficient of PU is positive; hence, the more students perceive MOOCs as useful, the greater their future intention to use it becomes.

\subsection{Discussion}

Firstly, the current study reveals that TAM, specifically PU, affects the intention to use MOOCs in the future, hence $\mathrm{H} 1$ has been accepted. We suggest that the more students find MOOCs useful, the more likely they will use MOOCs in the future. Moreover, regarding the Pearson correlation (Table 2), we found that PU and PEOU both have a strong relationship with the intention to use MOOCs in the future. Thus, hypothesis $\mathrm{H} 2$ has been also accepted. However, PU has a stronger and more direct correlation to the acceptability of MOOCs. This is completely consistent with previous studies. According to Aharony (2014), PU has a stronger impact on technology adoption than PEOU. The results of our research show that students will continue to use MOOCs if they feel that MOOCs bring them benefits such as providing more advanced study materials and obtaining useful knowledge or better grades in exams. Thus, if instructors expect their students to use MOOCs, they should elucidate the usefulness and ease of use of MOOCs to the learners, to encourage them to adopt and eventually enroll in MOOCs in their curriculum.

Secondly, $\mathrm{H} 3$ and $\mathrm{H} 4$ focused on learning strategies but only $\mathrm{H} 4$ were accepted. Although deep learners are the ones who find MOOCs easy to use and useful, they are less likely to adopt MOOCs in the future. Accordingly, to boost students' intention to use MOOCs in the future, boards of curriculum planning and development should consider the courses they plan to apply. If possible, they can let their students choose their own course in the given lists. Many previous studies have suggested that surface learning has not impact on the adoption of MOOCs (Aharony, 2016). The results of our research show that surface learning has a negative effect on the adoption of MOOCs in the future. Moreover, there is a strong connection between surface learners and TAM. It proves that surface learners find MOOCs easy to use and valuable, so they tend to participate more MOOCs. Another interesting fact was revealed in the current study was that the surface learning strategy is highly dependent on the number of courses that the student has ever experienced. In other words, the more courses students take on Coursera, the less their surface learning strategy becomes.

\section{CONCLUSION}

In conclusion, TAM, which is both PU and PEOU, was found to have influenced students' intention to enroll in future MOOCs. Specifically, perceived usefulness makes a great contribution to their likely enrollment in a MOOC. Therefore, the program developers need to produce courses with the content that is closely connected to students' needs to facilitate their perceptions on MOOCs' relevance and usefulness. In addition, there is an inverse correlation between surface learning and future MOOC use, as the less surface learning participants experience, the more probable it is that they will use MOOCs in the future. The research has also discovered a way to minimize students' surface learning strategies in the process of studying MOOCs.

This study has several limitations. The first is the study merely concentrated on courses while it is possible for the instructor to make impact on learners' attitudes. Secondly, while this study used a quantitative approach, it is suggested that further studies should be conducted with a mixed method approach to have a more insightful view and understanding. Finally, since the current study primarily focused on students' perception at a private university, we propose that for a broader view, the next study should be conducted at other public universities in Vietnam and even other nations for a global perspective. 
Conflict of Interest: No potential conflict of interest relevant to this article was reported.

Funding: The authors received no financial support for this article.

\section{REFERENCES}

Aharony, N., \& Bar-Ilan, J. (2016). Students' perceptions on MOOCs: An exploratory study. Interdisciplinary Journal of E-Learning and Learning Objects, 12(1), 145-162. Informing Science Institute. https://www.learntechlib.org/p/180848/

Aharony, N. (2009). The influence of LIS students' personality characteristics on their perceptions towards Web 2.0 use. Journal of Librarianship and Information Science, 41(4), 227-241. https://doi.org/10.1177/0961000609345088

Aharony, N. (2014a). Factors affecting the adoption of e-books by information professionals. Journal of Librarianship and Information Science, 47(2), 131-144. https://doi.org/10.1177/0961000614532120

Aharony, N. (2014b). Library and information science students' perceptions of m-learning. Journal of Librarianship and Information Science, 46(1), 48-61. https://doi.org/10.1177/0961000613518819

Aldowah, H., Al-Samarraie, H., Alzahrani, A. I., \& Alalwan, N. (2019). Factors affecting student dropout in MOOCs: a cause and effect decision-making model. Journal of Computing in Higher Education, 32(2), 429-454. https://doi.org/10.1007/s12528-019-09241-y

Al-Gahtani, S. (2016). Empirical investigation of e-learning acceptance and assimilation: A structural equation model. Applied Computing and Informatics, 12(1), 27-50. https://doi.org/10.1016/j.aci.2014.09.001

Bates, T. (2014). MOOCs: Getting to know you better. Distance Education, 35(2), 145-148. https://doi.org/10.1080/01587919.2014.926803

Bayne, S., \& Ross, J. (2014). MOOC pedagogy. Massive Open Online Courses: The MOOC Revolution, 11(2), 2326. https://doi.org/10.5070/d4112027189

Belanger, Y., \& Thornton, J. (2013). Bioelectricity: A quantitative approach. Duke University's first MOOC. http://dukespace.lib.duke.edu/dspace/bitstream/handle/10161/6216/Duke_Bioelectricity_MOOC_Fall2012.pdf

Chen, Y. (2014). Investigating MOOCs through blog mining. International Review of Research in Open and Distance Learning, 15(2), 85-106. https://doi.org/10.19173/irrodl.v15i2.1695

Davis, F. D. (1989). Perceived usefulness, perceived ease of use and user. acceptance of information technology. MIS Quarterly, 13(3), 319-340. https://doi.org/10.2307/249008

Dyer, R. A. D. (2014). Exploring the relevancy of massive open online courses (MOOCs): A Caribbean university approach. Information Resources Management Journal, 27(2), 61-77. https://doi.org/10.4018/irmj.2014040105

Glance, D., Forsey, M., \& Riley, M. (2012). The pedagogical foundations of massive open online courses. First Monday Journal, 18(5). https://doi.org/10.5210/fm.v18i5.4350

Hoi, V. N. (2020). Understanding higher education learners' acceptance and use of mobile devices for language learning: A Rasch-based path modeling approach. Computers \& Education, 146, 103761._https://doi.org/ 10.1016/j.compedu.2019.103761

Jordan, K. (2013). MOOC completion rates: The data. http://www.katyjordan.com/MOOCproject.html

Jordan, K. (2014). Initial trends in enrolment and completion of massive open online courses. The International Review of Research in Open and Distributed Learning, 15(1), 134-160. https://doi.org/10.19173/ irrodl.v15i1.1651

Kesim, M., \& Altınpulluk, H. (2015). A theoretical analysis of MOOCs types from a perspective of learning theories. Procedia - Social and Behavioral Sciences, 186, 15-19. https://doi.org/10.1016/j.sbspro.2015.04.056

Khawater, F. A. A. (2021). The effects of online learning on students' positive and negative online learning outcomes. International Journal of Research in Education Humanities and Commerce, 2(2), 23-26. https://www.ijrehc.com/ doc/ijrehc02_08.pdf

Markoff, J. (2013). Essay-grading software offers professors a break. The New York Times. https://www.nytimes.com/2013/04/05/science/new-test-for-computers-grading-essays-at-college-level.html

Marton, F., \& Säljö, R. (1976). On qualitative differences in learning: I-outcome and process. British Journal of Educational Psychology, 46(1), 4-11. https://doi.org/10.1111/j.2044-8279.1976.tb02980.x

Meyer, R. (2012). What it's like to teach a MOOC (and what the heck's a MOOC?). https://www.theatlantic.com/ technology/archive/2012/07/what-its-like-to-teach-a-mooc-and-what-the-hecks-a-mooc/260000/ 
Nguyen, T. (2015). The effectiveness of online learning; Beyond no significant difference and future horizons. MERLOT Journal of Online Learning and Teaching, 11(2), 309-319. http://jolt.merlot.org/Vol11no2/ Nguyen_0615.pdf

Pallant, J. (2007). SPSS Survival manual: A Step by Step Guide to data analysis using SPSS. Allen \& Unwin, Sabon by Bookhouse, Sydney.

Ross, J., Sinclair, C., Knox, J., Bayne, S., \& Macleod, H. (2014). Teacher experiences and academic identity: The missing components of MOOC pedagogy. MERLOT Journal of Online Learning and Teaching, 10(1), 56-68. https://doi.org/10.1007/s42438-020-00203-7

Sang, C., \& Tai, D. (2017). Online education: Which model will succeed? https://nhipcaudautu.vn/biz-tech/giao-ductruc-tuyen-mo-hinhnao-se-thanh-cong-3318137/

Sattari, A., Abdekhoda, M., \& Gavgani, V. Z. (2017). Determinant factors affecting the web based training acceptance by health students, applying the UTAUT model. International Journal of Emerging Technologies in Learning (iJET), 12(10), 112-126. https://doi.org/10.3991/ijet.v12i10.7258

Siemens, G. (2013). Massive open online courses: Innovation in education? In R. McGreal, et al. (Eds). Open Educational Resources: Innovation, Research and Practice, 1, 5-15. https://doi.org/10.7551/mitpress/ 9202.003.0005

Taylor, S., \& Todd, P. A. (1995). Understanding information technology usage: A test of competing models. Information Systems Research, 6(2), 144-176. https://doi.org/10.1287/isre.6.2.144

Thompson, B. (2000). Ten Commandments of Structural Equation Modeling. In L. Grimm, \& P. Yarnold (Eds.), Reading and Understanding More Multivariate Statistics, 261-284. Washington DC: American Psychological Association.

University of Pennsylvania Graduate School of Education, Press Room (2013). Penn GSE study shows MOOCs have relatively few active users, with only a few persisting to course end. https://www.gse.upenn.edu/pressroom/pressreleases/2013/12/penn-gse-study-shows-MOOCs-have-relatively-few-active-users-only-few-persisti

Vululleh, P. (2018). Determinants of students' e-learning acceptance in developing countries: An approach based on Structural Equation Modeling (SEM). International Journal of Education and Development using ICT, 14(1). Open Campus, The University of the West Indies, West Indies. https://www.learntechlib.org/p/183560/

Warburton, K. (2003). Deep learning and education for sustainability. International Journal of Sustainability in Higher Education, 4(1), 44-56. https://doi.org/10.1108/14676370310455332

Wu, B., \& Chen, X. (2017). Continuance intention to use MOOCs: Integrating the technology acceptance model (TAM) and task technology fit (TTF) model. Computers in Human Behavior, 67, 221-232. https://doi.org/ 10.1016/j.chb.2016.10.028

Yang, Y. F., \& Tsai, C. C. (2010). Conceptions of and approaches to learning through online peer assessment. Learning and Instruction, 20(1), 72-83. doi:10.1016/j.learninstruc.2009.01.003 